\title{
ELIMINATION OF LOCAL DEFORMATIONS OF BUCKLING TYPE BY MEANS OF ELECTRODYNAMIC TREATMENT
}

\author{
L.M. LOBANOV, N.A. PASHCHIN, O.L. MIKHODUJ and T.G. SOLOMIJCHUK \\ E.O. Paton Electric Welding Institute, NASU \\ 11 Bozhenko Str., 03680, Kiev, Ukraine. E-mail: office@paton.kiev.ua
}

\begin{abstract}
Non-uniform heating of hull structures in welding of longitudinal-transverse framing promoted appearance of residual local deformations (buckling) in form of alternating bulges and indentations at adjacent sections of a panel. They have negative effect on service properties and appearance of the structure as well as hydrodynamic characteristics of ships, reducing their speed to $10 \%$. Traditional methods of buckling removal such as thermal and cold straightening have series of disadvantages (noise, vibration, significant consumption of energy carriers). Development of new methods of buckling straightening based on minimum energy consumption is a relevant task. Electrodynamic treatment is one such methods. Aim of present work is a study of effect of electrodynamic treatment on reduction of local deformations of buckling type in welded joints from aluminum alloys and low-carbon steels. Square samples of tee welded joints from AMg6 alloy and low-carbon steel St3 were used for simulation of buckling with different sign and deflection value. Mode of treatment corresponded to energy accumulated by storage, not exceeding $800 \mathrm{~J}$. Effect of distribution of electrodynamic impacts, namely spot, circular and spiral ones, over sample surface on change of buckling form was investigated. Spot scheme has the lowest efficiency, and circular and spiral ones can be compared by efficiency. Comparative analysis showed that consumption of energy in electrodynamic treatment is significantly lower than in use of traditional methods of straightening. 10 Ref., 1 Table, 7 Figures.
\end{abstract}

Key words: local deformations, buckling, low-carbon steel, aluminum alloy, electrodynamic treatment, treatment scheme, pulse energy, traditional straightening methods

Non-uniform heating of hull structures in welding of longitudinal-transverse framing promoted appearance of residual local deformations (buckling) in form of alternating bulges and indentations at adjacent sections of a panel. They have alternating nature and are directed to framing as well as in opposite direction. It is a well-known fact [1] that buckling of structure takes place as a result of loss of panel stability between framing under effect of compressive stresses and has negative effect on working capacity, service characteristics and appearance of structure as well as hydrodynamic characteristics of ships, reducing their speed to $10 \%$. At that, number of welded sheet hulls are designed with such combination of elements, at which appearance of buckling of more than allowable level is inevitable. Straightening is the main method for reduction of deformations in such structures [2].

Straightening of buckling using local heating with dynamic impact has found the widest distribution in shipbuilding. It is related with application of rough labor, high level of noise (120$140 \mathrm{~dB})$ and structure vibration. Taking into account that straightening in the closing stages of welding works is mainly carried out at ship-way, when large number of operating personnel is engaged in assembly and completion, it promotes for rough labor conditions, results in extension of completion period and, in separate cases, promotes unallowable damages of surface being treated.

Application of thermal straightening eliminates noise and vibration, but being related with negative thermal effect on operating personnel, significant overexpenditure of heat building gas mixtures during heat sink into environment and technological equipment. Besides, application of heat in straightening of structures from aluminum alloys is insufficiently effective in series of cases due to their high heat conduction. Indicated disadvantages are also typical for thermal straightening by «idle» rolls using welding arc heating.

Using of enumerated straightening methods is connected with sufficiently noticeable damages of surface of welded structures, caused by dynamic impact of mechanical tool as well as thermal-deformation cycles as a result of welding heating.

Application of cold straightening with stretching benches for buckling removal is limited by geometry peculiarities of this type of change of form, among which are their localizing and significant dimensions of structure, as well as high cost of equipment. 
Therefore, development of novel methods of buckling straightening, based on minimum energy consumption and providing minimum damage to surface to be treated, is sufficiently relevant. Treatment of structures using pulse electric and magnetic fields [3-6] can be referred to them. Electrodynamic treatment (EDT) is its variety.

Earlier the investigations were carried out in relation to effect of EDT on regulation of longitudinal and transverse buckling of butt welded joints from aluminum alloys and structural steels [7]. Perspective of application of EDT for reduction of such types of buckling was confirmed by work results.

Aim of the present work is a study of EDT impact on reduction of local deformations of buckling type in welded joints from aluminum alloys and low-carbon steel used in shipbuilding.

Samples with tee welded joints from aluminum alloy AMg6 and low-carbon steel St3 were used for investigations and simulation of bucking with deflection $f$ (Figure 1). They represent itself a plate with four stiffeners welded by fillet welds. Size of plate and stiffeners are given in Figure 1, $a$. Change og form of samples from AMg6 alloy with plates of equal thickness $\delta$ and stiffeners of two dimension-types, corresponding to $\delta=2$ and $4 \mathrm{~mm}$, and steel St3 $(\delta=2 \mathrm{~mm})$ of one dimension-type was investigated. At that, deflection of plate $f$ in direction to stiffeners was taken with sign «+» and that with sign «-» in direction from stiffeners. Deflection in samples from AMg6 alloy $(\delta=4 \mathrm{~mm})$ was set in direction to stiffeners as well as from them, and that in samples from AMg6 alloy and steel St3 $(\delta=2 \mathrm{~mm})$ was taken only in direction to stiffeners.

It can be assumed, based on [8], providing parametric characteristics of pressure pulses at electrodynamic impacts, as well as data from [9], showing that metal at outer contact surface with electrode is subjected to compression in radial direction in sheet plane, that EDT application is reasonable for zones with maximum curvature of buckling, and direction of electrodynamic impact application should be turned to $f$ reduction.

Fillet welds of samples from AMg6 alloy were carried out by manual TIG welding in argon at 130 A current and $1.3 \mathrm{~mm} / \mathrm{s}$ speed using $3 \mathrm{~mm}$ diameter filler rod of SvAMg6 grade. Geometry characteristics of change of buckling form, corresponding to different $f$ signs, were provided with the help of different combinations of bead deposition. Joining of samples from St3 steel was performed by manual welding using coated electrode of Monolit RTs grade of $3 \mathrm{~mm}$ diameter at 120 A current and $1.5 \mathrm{~mm} / \mathrm{s}$ speed.

EDT (Figure 2) was carried out with the help of flat inductor equipped by electrode from M1

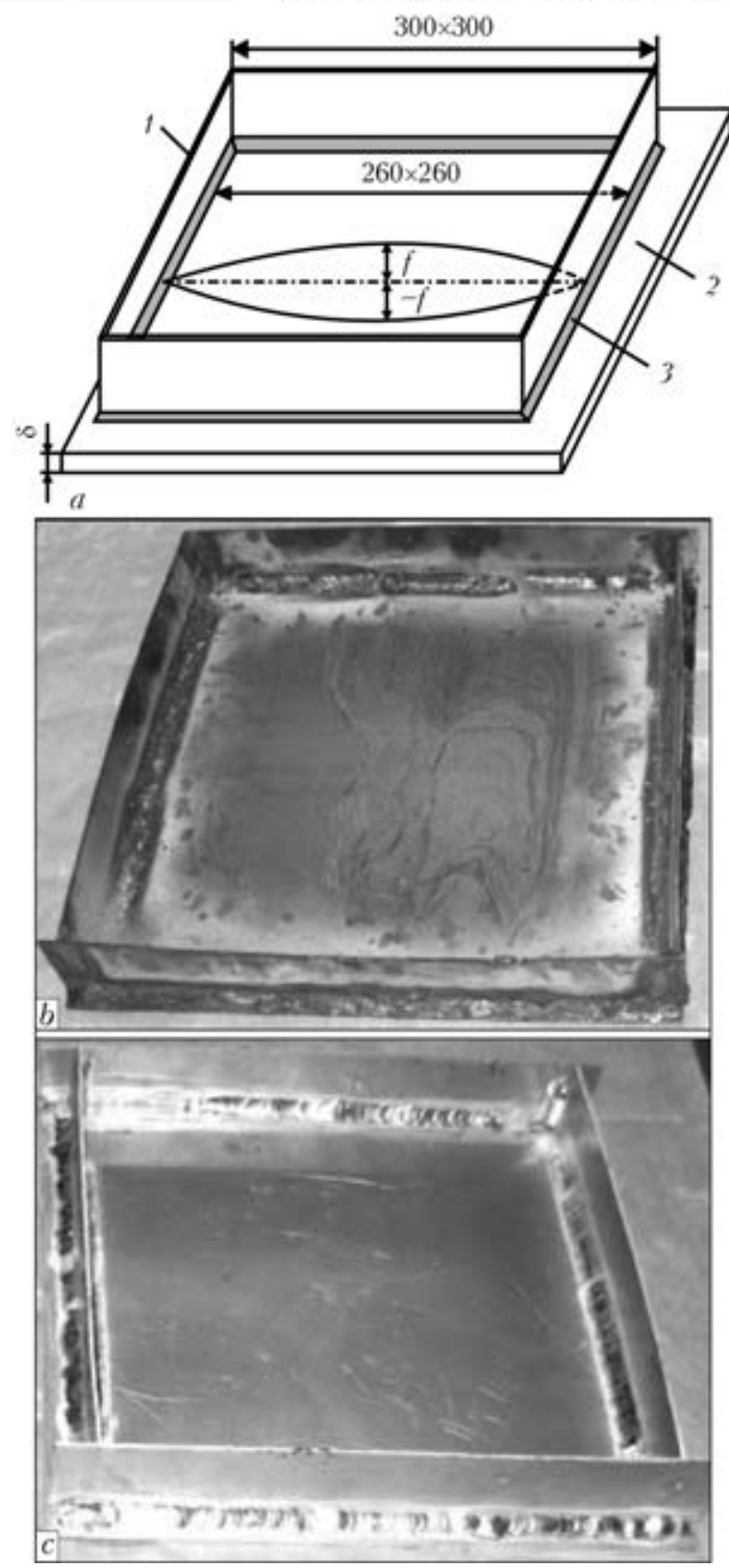

Figure 1. Scheme of samples of welded joints with buckling type deformation ( $a$ : 1 - stiffener; 2 - plate; 3 - fillet weld) and appearance of samples from steel St3 (b) and alloy AMg6 (c)

grade copper with semi-spherical tip, and capacitor storage was used as a pulse generator [6]. EDT mode corresponded to energy accumulated by capacitor storage $E_{k 1}$, necessary for realizing of single electrodynamic impact $(n=1)$, not exceeding $800 \mathrm{~J}$. Value of accumulated energy $E_{\mathrm{EDT}}$, necessary for realizing of series from $n$ electrodynamic impacts, was calculated from expression

$$
E_{\mathrm{EDT}}=E_{k 1} n \text {. }
$$

Distance between the zones of electrodynamic impacts was varied from 10 (for St3) to $30 \mathrm{~mm}$ (for $\mathrm{AMg} 6$ ), that provided stable results of straightening on length of treated section of sample surface. 


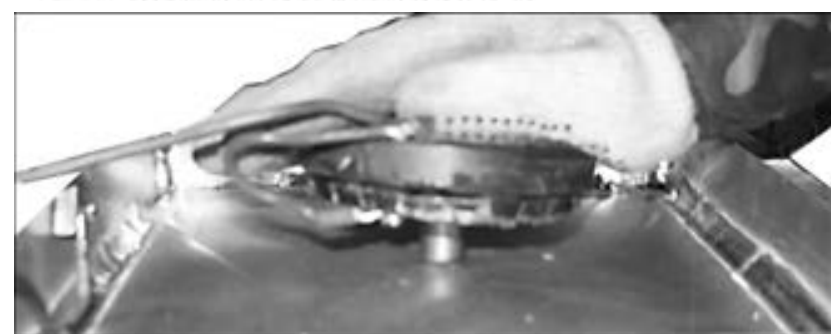

Figure 2. EDT of AMg6 alloy samples with buckling ( $\delta=$ $=2 \mathrm{~mm}$ )

Influence of different schemes of distribution of electrodynamic impacts over sample surface on change of buckling form was investigated. Deflections $f$ in cross-section of the samples were controlled by standard procedure using ruler and caliper. Three schemes of EDT of sample surface, i.e. spot, circular and spiral in direction from center to edges, were investigated using samples from AMg6 alloy with $\delta=4 \mathrm{~mm}$.

Spot EDT was realized by means of application of series from five electrodynamic impacts $(n=5)$ in plate center, where initial bucking had typical deflection form with maximum initial value $f_{\max }=-5 \mathrm{~mm}$ (Figure 3 , curve 1 ) in direction from the stiffeners. Figure 3 represents change of buckling form in sample, where EDT zone corresponds to $x=100 \mathrm{~mm}$ coordinate on abscissa axis. As can be seen, maximum efficiency of EDT takes place at $n=1$, that corresponds to $f=-4 \mathrm{~mm}$ (Figure 3 , curve 2 ) and monotonously decreases to $f=-2 \mathrm{~mm}$ at $n=5$ (Figure 3, curves $3-5)$. Change of typical form of deflection takes place at $n=3-5 \mathrm{~mm}$, that is accompanied by decrease of $f$ values in zone of treatment and their increase outside the zone, in sections of corresponding coordinates $x=75$ and $125 \mathrm{~mm}$.

This can be explained based on theory of normal contact of inelastic bodies [9] for the case of interaction of semi-spherical indenter (in our case - electrode) with elasto-plastic media. It is shown that wrought metal at contact interactions is displaced by indenter to free surface be-

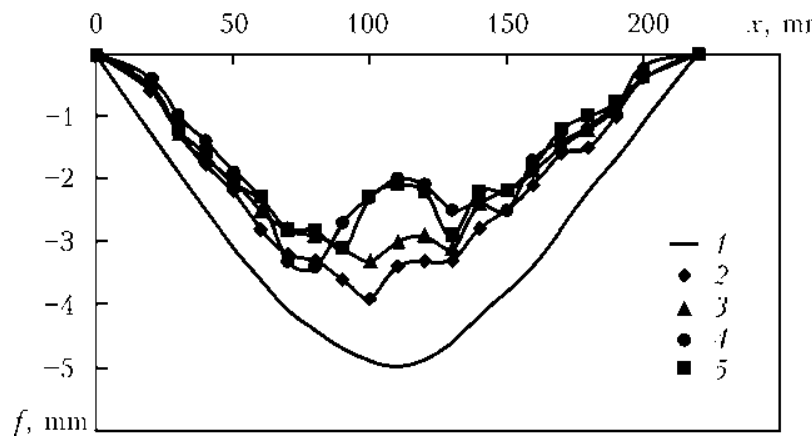

Figure 3. Change of buckling form $f$ in sample from AMg5 alloy $(\delta=4 \mathrm{~mm})$ after EDT of plate center: 1 - initial $f_{\text {max }}$ values; $2-f$ after EDT at $n=1 ; 3-$ same, $n=2$; $4-n=3 ; 5-n=4$ and 5 hind the contact zone. At that, plastic flow of the displaced material takes place along the indenter edges. EDT cycle, corresponding to $n>$ $>3$, includes this mechanism, which is characterized by metal displacement behind the treatment zone and local distortion of buckling surface in sections corresponding to $x=75$ and $125 \mathrm{~mm}$ coordinates (see Figure 3). Repeated plastic flow in zone of electrode contact, observed at $n=4-5$, takes place under conditions of constrained deformation and its effect on surface profile is insignificant, that can be seen from similarity of curves 4 and 5 in Figure 3.

Besides work [10] shows that EDT of AMg6 alloy promotes significant increase of $\sigma_{0.2}$ value, and interaction of buckling with electrode at treatment cycles, corresponding to $n>3$, proceeds to elastic stage without significant residual change of form. Thus, scheme of local multiple application of electrodynamic impact to selected section on sample surface allows for not more than $60 \%$ reduction of $f$ initial values.

This EDT scheme is not efficient, since allowable $f$ values should correspond to the following condition, according to norms of local deformation, for example OST 5.9079-72:

$$
f=a / 80,
$$

where $a$ is the size of spacing (distance between the stiffeners)

The allowable $f$ value should not exceed $3.75 \mathrm{~mm}$ for samples considered in this work, which is close to curve 5 in Figure 3, and being maximum allowable for spot EDT. An advantage of given scheme is the minimum (in comparison with other schemes) quantity of accumulated energy $E_{\mathrm{EDT}}$ of capacity storage, necessary for change of form, shown in Figure 3, which does not exceed $4000 \mathrm{~J}$ at $n=5$ according to (1).

Circular scheme of EDT was realized by means of application of three series of electrodynamic impacts in form of concentric circumferences with different radius $R$ on sample surface (Figure 4, a) with initial buckling, form and $f_{\max }$ value of which (Figure 4, b, curve 1) were similar to considered in Figure 3. $R$ values were equal 15, 50 and $90 \mathrm{~mm}$, and $n$ and $E_{\mathrm{EDT}}$ values (according to (1) for EDT of set circumferences made 8, 30, 55 and $6.4 \cdot 10^{2}, 2.4 \cdot 10^{4}, 4.4 \cdot 10^{4} \mathrm{~J}$, respectively.

As can be seen from Figure 4, $b, f$ values steadily reduce with rise of $R$, which is accompanied by change of deflection sign and gradual change of its form from typical to wave-like. Using of $R=15 \mathrm{~mm}$ provides for $f$ values (Figure $4, b$, curve 2) and change of buckling form close to shown in Figure 3 for spot EDT at $n=1-3$, that is explained by low $R$ value. Form of deflection 

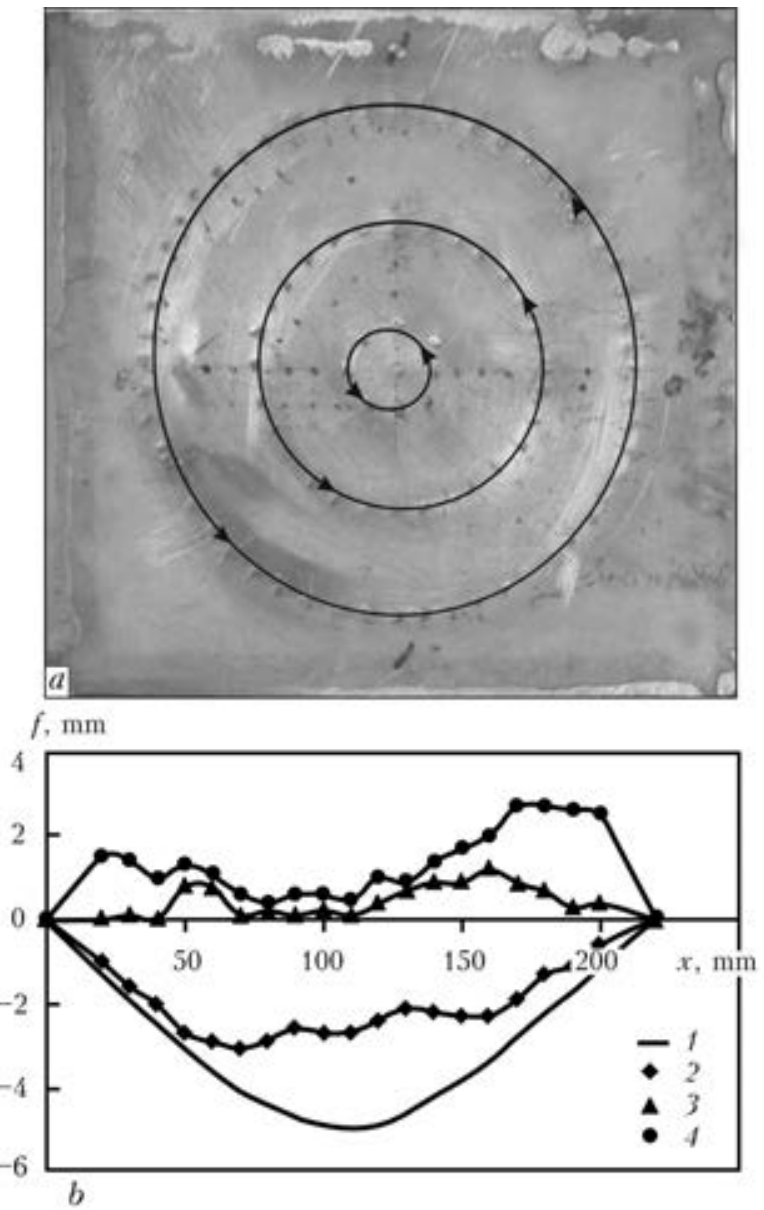

Figure 4. Appearance $(a)$ and change of buckling form (b) in AMg6 alloy sample $(\delta=4 \mathrm{~mm})$ after circular EDT at change of radius $R: 1-$ initial $f_{\max }$ values; $2-f$ after EDT at $R=$ $=15 \mathrm{~mm} ; 3-$ same, $R=50 \mathrm{~mm} ; 4-R=90 \mathrm{~mm}$

is close to wave-like at sign change with rise of $R$ up to $50 \mathrm{~mm}$ (Figure $4, b$, curve 3 ), that corresponds to central part of plate, and $f$ value achieves $1 \mathrm{~mm}$. EDT at $R=90 \mathrm{~mm}$ (Figure 4, $b$, curve 4) was carried out for investigation of possibility of buckling removal, $f_{\max }$ of which exceed indicated in Figure 4, $b$. Using of scheme of concentric circumferences at discrete increase of $R$ value allows for virtually complete elimination of local deformation as well as application of given scheme at increased $f_{\max }$.

It can be concluded, based on analysis of data from Figure 4, $b$, that EDT of central part of plate is supposed to be the most efficient at $R=$ $=50 \mathrm{~mm}$ in comparison with $R=15$ and $90 \mathrm{~mm}$. At the same time, considering data of Figure 3, it can be deduced that EDT in wide range of $R$ values can rise the efficiency of electrodynamic impact at increased initial $f$ values and area of surface to be treated.

Evolution of two previous schemes is a spiral EDT, realized by means of application of electrodynamic impacts to treated surface in form of spiral with alternating radius $R$, which spreads from center to sample edges (Figure $5, a$ ). At

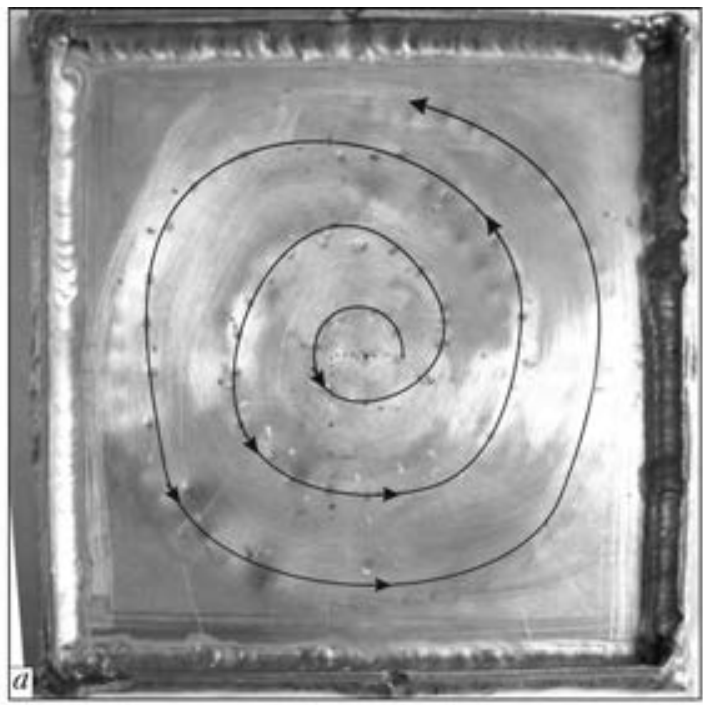

f. $\mathrm{mm}$

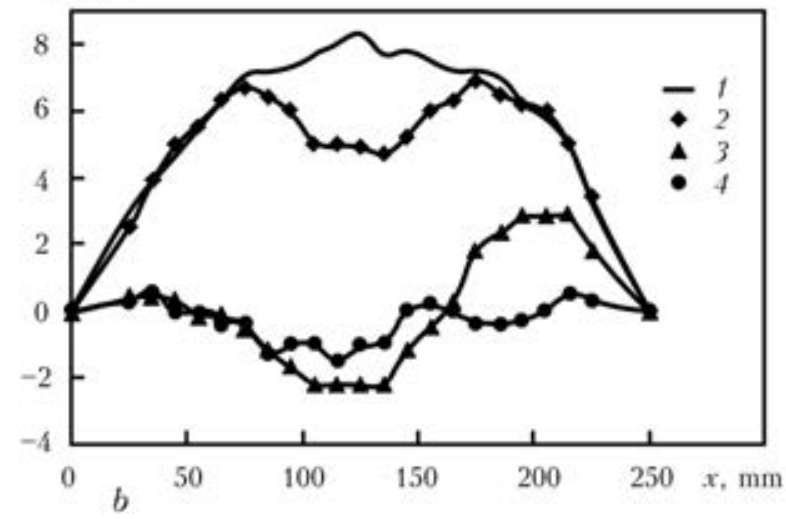

Figure 5. Appearance ( $a$ ) and change of buckling form (b) in AMg6 alloy sample $(\delta=4 \mathrm{~mm})$ after spiral EDT at change of radius $R: 1-$ initial $f_{\max }$ values; $2-f$ after EDT at $R=15 \mathrm{~mm} ; 3-$ same, $R=50 \mathrm{~mm} ; 4-R=90 \mathrm{~mm}$

that, parabolic form of initial buckling was set in stiffener direction and $f_{\max }$ value (Figure 5, $b$, curve 1) achieved $8 \mathrm{~mm}$. Change of $f$ was registered at $R=15,50$ and $90 \mathrm{~mm}$ for comparison with circular EDT, shown in Figure 4. Values of $n$ and $E_{\mathrm{EDT}}(1)$ for EDT at $R=15,50$ and $90 \mathrm{~mm}$ made $8,30,22$ and $6.4 \cdot 10^{2}, 2.4 \cdot 10^{4}, 1.7 \cdot 10^{4} \mathrm{~J}$, respectively.

As can be seen from Figure 5, b, nature of form changing and $f$ values is close to circular EDT scheme without consideration of deflection sign. $f$ values (see Figure 5, $b$, curve 2 ) reduce in central zone of the buckling from 8 to $5 \mathrm{~mm}$ with preservation of deflection sign in achievement of $R=15 \mathrm{~mm}$. Change of form at EDT of middle part of the buckling, corresponding to increase of $R$ up to $50 \mathrm{~mm}$ (see Figure $5, b$, curve 3), varies the nature from parabolic to sineshaped, that is accompanied by steady growth of values of negative half-wave of amplitude $f$ from 0 to -2 and positive one from 0.5 to $3.0 \mathrm{~mm}$. Asymmetry of form changing, presented in $\mathrm{Fi}^{-}$ gure $5, b$, curve 3 , is removed at EDT under conditions of $R$ growth up to $90 \mathrm{~mm}$ (curve 4), 
SCIENTIFIC AND TECHNICAL

Values of $f_{0}$ and $f_{\mathrm{EDT}}$ deflections and $\Sigma E_{k}$ energy at different types of straightening of AMg6 alloy and St3 steel

\begin{tabular}{|c|c|c|c|c|c|c|c|}
\hline $\begin{array}{c}\text { Number of } \\
\text { item }\end{array}$ & Metal & $\delta, \mathrm{mm}$ & Types of EDT straightening & $f_{0}, \mathrm{~mm}$ & $f_{\mathrm{EDT}}, \mathrm{mm}$ & $\Sigma E_{k}, \mathrm{~kJ}$ & $\Sigma E_{k} / \Delta f, \mathrm{~kJ} / \mathrm{mm}$ \\
\hline 1 & AMg6 & 4 & Spot & -5 & -3 & 4.0 & 2 \\
\hline 2 & Same & 4 & Circular & -5 & 1 & 74.4 & 12 \\
\hline 3 & $\gg$ & 4 & Spiral & 8 & -1 & 47.4 & 5,2 \\
\hline 4 & $\gg$ & 2 & Same & 8 & -1 & 31.2 & 3 \\
\hline 5 & $\gg$ & 2 & $\gg$ & 8 & -2 & 115 & 11.5 \\
\hline 6 & St3 & $3-5$ & Impact with preheating & \multicolumn{2}{|c|}{$\mathrm{N} / \mathrm{D}$} & $41,160[1]$ & $\mathrm{N} / \mathrm{D}$ \\
\hline 7 & AMg5 & $3-5$ & Heat & \multicolumn{2}{|c|}{ Same } & $15,876[1]$ & Same \\
\hline
\end{tabular}

at which sine curve becomes symmetric with excursion to $2 \mathrm{~mm}$, and its positive half-wave does not exceed $0.5 \mathrm{~mm}$. This is significantly lower than allowable $f$ values at used spacing $a=$ $=300 \mathrm{~mm}$ according to (1).

The most efficient from point of view of $f$ reduction, the same as for circular scheme, is EDT of central part of the plate at $R$ growth to $50 \mathrm{~mm}$ (see Figure $5, b$, curve 3 ) in comparison with $R=$ $=15$ (curve 2) and $90 \mathrm{~mm}$ (curve 4 ). It should be noted that application of EDT in compressive stress zone near the stiffeners $(R=90 \mathrm{~mm})$ can provide corrective impact, directed at local straightening of sections of buckling surface.

Comparison of EDT schemes, given in $\mathrm{Fi}$ gures 3-5, allows concluding that spot scheme is the least efficient and energy consuming, and circular and spiral ones can be matched in efficiency, however the latter one requires lower $E_{k}$ value for realizing. Thus, spiral EDT scheme is supposed to be the most relevant for straightening of local buckling deformations.

EDT of samples from AMg6 alloy $(\delta=$ $=2 \mathrm{~mm})$ and St3 steel $(\delta=2 \mathrm{~mm})$ was carried out using spiral scheme, similar to shown in $\mathrm{Fi}^{-}$ gure 5. Receiving of indices of $f_{\max }$ reduction, close to presented in Figure 5, required lower $E_{k}$ value for AMg6 samples in comparison with

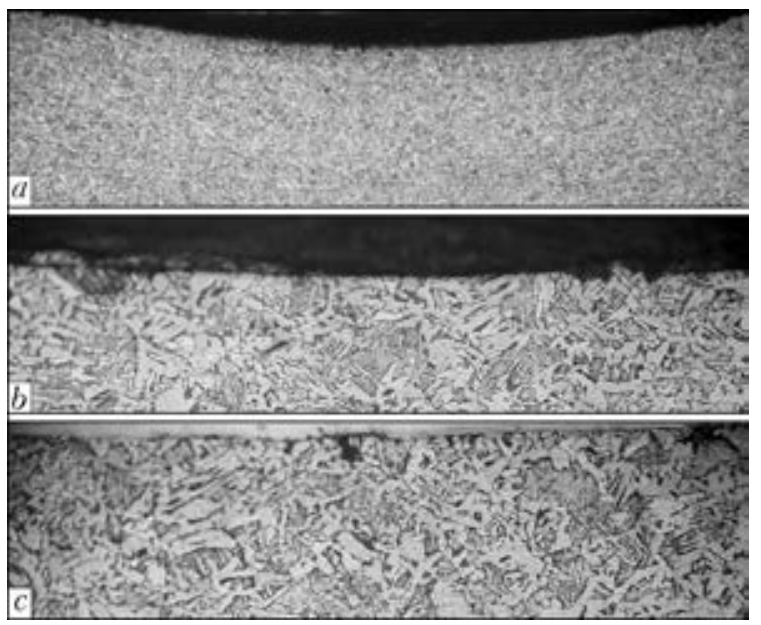

Figure 6. Microstructure of steel St3 after EDT with insert from M1 copper $0.5 \mathrm{~mm}$ thick: $a$ - general appearance of indentation $(\times 50) ; b-$ center of indentation $(\times 200) ; c-$ St3 in initial condition $(\times 200)$
$4 \mathrm{~mm}$ ones in contrast to St3 samples, where $E_{k}$ value is significantly higher.

Compared data on EDT impact on initial $f_{0}$ and residual $f_{\mathrm{EDT}}$ deflections at different configurations of EDT schemes as well as corresponding to schemes $\Sigma E_{k}$ values after full cycle of treatment are represented in the Table. Absolute values of deflection change $\Delta f=I f_{0}-f_{\mathrm{EDT}} I$ and specific energy efficiency $\Sigma E_{k} / \Delta f$ at different EDT schemes were determined based on $f_{0}$ and $f_{\text {EDT }}$ data. Besides, the Table also shows $\Sigma E_{k}$ values at heat and impact straightening with preheating of surface area of structure from AMg5 alloy $(\delta=$ $=3-5 \mathrm{~mm}$ ), being equal $0.9 \mathrm{~m}^{2}$, that is close to geometry characteristics of studied samples.

Analysis of the Table data allows concluding that $\Sigma E_{k}$ at EDT is significantly lower than $\Sigma E_{k}$ corresponding to traditional types of straightening (see items 6 and 7) at equal area of surface to be treated. It indicates satisfactory energy efficiency of EDT process. At that, even the least efficient spot scheme of EDT of AMg6 alloy $(\delta=$ $=4 \mathrm{~mm}$ ) with minimum energy input $\Sigma E_{k}$ (item 1) allows providing for $f_{0}$ reduction to that corresponding to requirements of reference documents, for example OST 5.9079-72. At the same time, the values of energy consumption per $1 \mathrm{~mm}$ of deflection $\Sigma E_{k} / \Delta f$ for AMg6 alloy $(\delta=2 \mathrm{~mm})$ using spiral scheme (item 4 ) are close to $\Sigma E_{k} / \Delta f$ at spot scheme for $\delta=4 \mathrm{~mm}$ (item 1 ). Comparison of $\Sigma E_{k} / \Delta f$ of circular (item 2) and spiral (item 3) EDT for AMg6 alloy $(\delta=4 \mathrm{~mm})$ shows that the latter has 2 times less consumption at approximately equal process efficiency.

EDT of St3 steel at $\delta=2 \mathrm{~mm}$ (item 5) is the most energy-consuming at the level of accumulated energy. In it $\Sigma E_{k}$ and $\Sigma E_{k} / \Delta f$ indices are 4 times higher than similar ones for AMg6 alloy at equal thickness (item 4 ) and $\Sigma E_{k} / \Delta f$ values are comparable with circular scheme for AMg6 alloy at $\delta=4 \mathrm{~mm}$.

It can be concluded, based on [6], that electric-pulse impacts have in whole positive effect on structure of structural materials. At the same time, formation of semi-spherical indentations of up to $0.3 \mathrm{~mm}$ depth is observed in localized sec- 


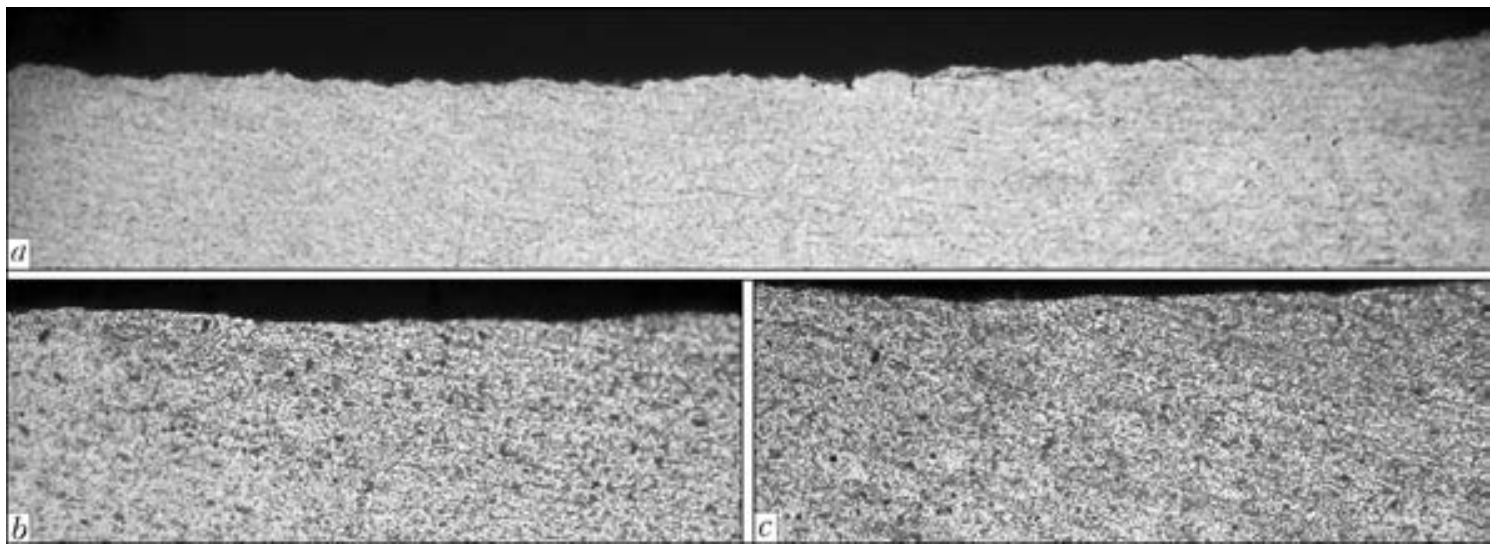

Figure 7. Microstructure of AMg6 alloy after EDT with M1 copper insert $0.5 \mathrm{~mm}$ thick: $a$ - general appearance of indentation $(\times 25) ; b-$ structure in indentation zone $(\times 500) ; c-$ alloy AMg6 in initial condition $(\times 500)$

tions of zone of electrodynamic impact. They, in some cases, can influence the service characteristics of hulls. Optimizing of EDT technology based on mentioned above is directed to reduction of surface depth in zone of contact interaction.

Investigation was carried out on a method for minimizing of indentation depth. It is based on application of technological inserts from M1 grade copper, being set between electrode and metal to be treated.

Figure 6 shows the fragments of structure of St3 steel, treated through copper insert $0.5 \mathrm{~mm}$ thick at pulse energy $E_{k}=800 \mathrm{~J} .0 .1 \mathrm{~mm}$ depth indentation (see Figure 6, $a$ ) was formed in EDT zone. No metal changes were found on its surface. Examination of metal structure in EDT zone in the middle of indentation (see Figure $6, b$ ) shows its identity to ferrite-pearlite structure of initial metal (see Figure 6, $c$ ).

Indentation of up to $0.3 \mathrm{~mm}$ depth (Figure 7 , a) was formed on AMg6 surface after EDT using $0.5 \mathrm{~mm}$ thick inserts. No change of structure was found on surface of indentation. Microstructure of metal after EDT (Figure 7, $b$ ) and in the initial condition (Figure $7, c$ ) consists of solid $\alpha$-solution, in which $\beta$-phase $\left(\mathrm{Mg}_{5} \mathrm{Al}_{8}\right)$ and $\mathrm{Mg}_{2} \mathrm{Si}$ phase inclusions were observed.

Thus, application of copper inserts, providing virtually complete removal of EDT impact on surface structure of materials to be treated and minimizing indentation depth (see Figures 6 and 7), can be recommended for EDT technologies, using which minimum damageability of treated surface of welded hulls is allowed.

\section{Conclusions}

1. Effect of different EDT schemes on reduction of local deformations of buckling type in samples from AMg6 alloy and St3 steel, in particular, spot, circular and spiral ones in direction from center to edges, was investigated. It is determined that spot scheme is the least effective and energy-consuming, and circular and spiral ones can be compared by efficiency, but the latter requires lower energyconsumption for its realizing. Spiral EDT scheme is supposed to be the most relevant for straightening of local buckling deformations.

2. It was determined, based on data of comparative analysis, that energy consumption at EDT is significantly lower than in traditional straightening, such as heat and impact with preheating.

3. Using of metallographic analysis of $\mathrm{mi}^{-}$ crosections of AMg6 alloy and St3 steel allowed determining that application of technological inserts from M1 grade copper at EDT provides for virtually complete elimination of electrodynamic impacts on structure of metal to be treated.

1. Mikhajlov, V.S. (1972) Straightening of hull welded structures. Moscow: Sudostroenie.

2. Makhnenko, O.V., Muzhichenko, A.F., Seyffarth, P. (2009) Application of mathematical modeling in thermal straightening of shipbuilding panels. The Paton Welding J., 1, 6-11.

3. Tang, F., Lu, A.L., Mei, J.F. et al. (1998) Research on residual stress reduction by a low frequency alternating magnetic field. J. Mat. Proc. Technol., 74, $255-258$.

4. Antonov, Yu.A., Rogozin, Yu.I. (2001) Pulse method of residual stress removal. Fizika $i$ Khimiya Obrab. Materialov, 3, 91-95.

5. Stepanov, G.V., Babutsky, A.I., Mameev, I.A. (2004) Non-stationary stress-strain state in long bar caused by electric current pulses of high density. Problemy Prochnosti, 4, 60-67.

6. Strizhalo, V.A., Novogrudsky, L.S., Vorobiov, E.V. (2008) Strength of materials at cryogenic temperatures considering the impact of electromagnetic fields. Kiev: IPP.

7. Lobanov, L.M., Pashchin, N.A., Mikhoduj, O.L. (2013) Electrodynamic straightening of elements of sheet welded structures. The Paton Welding J., 9, $18-23$.

8. Lobanov, L.M., Pashchin, N.A., Cherkashin, A.V. et al. (2012) Efficiency of electrodynamic treatment of aluminium alloy AMg6 and its welded joints. Ibid.,

9. Johnson, K.L. (1989) Contact mechanics. Moscow: Mir

10. Lobanov, L.M., Pashchin, N.A., Mikhoduj, O.L. (2012) Influence of loading conditions on deformation resistance of alloy AMg6 in electrodynamic treatment. Problemy Prochnosti, 5, 15-26.

Received 20.06.2014 